\title{
The Korean herbal medicine, Do In Seung Gi-Tang, attenuates atherosclerosis via AMPK in high-fat diet-induced $\mathrm{ApoE}^{-/-}$ mice
}

Sun Haeng Park ${ }^{1,2}$, Yoon-Young Sung ${ }^{1}$, Seol Jang ${ }^{1}$, Kyoung Jin Nho ${ }^{1}$, Go Ya Choi ${ }^{3}$ and Ho Kyoung Kim ${ }^{*}$

\begin{abstract}
Background: Do In Seung Gi-Tang (DISGT) is an herbal mixture of traditional Korean medicine that is composed of Rheum undulatum Linne, Prunus Persica (L.) Batsch, Conyza canadensis L., Cinnamomum Cassia Presl, and Glycytthiza uralensis Fischer (8: 6: 4: 4: 4 ratio). We investigated the effect of DISGT on vascular inflammation and lipid accumulation in apolipoprotein E-deficient $\left(\mathrm{ApoE}^{-/-}\right)$mice.

Methods: $\mathrm{ApoE}^{-1-}$ mice that were fed a high-fat diet (HFD) were treated with DISGT (300 mg/kg/day) or statin $(10 \mathrm{mg} / \mathrm{kg} / \mathrm{day})$ for 16 weeks. Serum lipid levels were analyzed. Oil Red O staining was used to evaluate atherosclerotic lesions and lipid accumulation in the aorta and liver, respectively. The expression of adhesion molecules (intercellular adhesion molecule-1 [ICAM-1], vascular cell adhesion molecule-1 [VCAM-1], and E-selectin), fatty acid synthase (FAS), adenosine monophosphate-activated protein kinase (AMPK), and acetyl-coA carboxylase (ACC) in the aorta or liver tissues was measured by western blot analysis. Lipid synthesis and inflammatory responses were assessed by immunohistochemistry and hematoxylin \& eosin staining, respectively.

Results: Treatment of HFD-fed mice with DISGT significantly lowered body weight, liver weight, and the levels of lipids, including total cholesterol, low-density lipoprotein-cholesterol, and triglycerides. Glucose levels were also lowered. In the aorta, DISGT attenuated atherosclerotic lesions and reduced the expression of ICAM-1, VCAM-1, and E-selectin. Moreover, DISGT decreased lipid accumulation, inflammatory responses, and FAS levels, and it activated AMPK and reduced ACC expression in liver tissues.

Conclusions: The beneficial, anti-lipolytic, and anti-inflammatory effects of DISGT were mediated by the AMPK pathway. As a result, the expression of inflammatory factors was reduced. Our data provide evidence that DISGT may have strong therapeutic potential in treating vascular diseases, such as atherosclerosis.
\end{abstract}

Keywords: Atherosclerosis, Apolipoprotein E-deficient mice, Adenosine monophosphate-activated protein kinase, Do In Seung Gi-Tangm, Vascular inflammation

Abbreviations: ACC, Acetyl-COA carboxylase; AMPK, Adenosine monophosphate-activated protein kinase; ApoE, Apolipoprotein E; FAS, Fatty acid synthase; HDL, High-density lipoprotein; ICAM, Intercellular adhesion molecule; KIOM, Korea Institute of Oriental Medicine; LDL, Low-density lipoprotein; T-chole, Total cholesterol; VCAM, Vascular cell adhesion molecule

\footnotetext{
* Correspondence: hkkim@kiom.re.kr

${ }^{1}$ Mibyeong Research Center, Korea Institute of Oriental Medicine, 1672

Yuseong-daero, Yuseong-gu, Daejeon 305-811, South Korea

Full list of author information is available at the end of the article
} 


\section{Background}

Do In Seung Gi-Tang (DISGT; Tao He Cheng Qi-Tang; Chinese) is used in traditional Korean medicine to treat blood stasis by promoting blood circulation. Blood extravasation in traditional Korean medicine refers to the ability to encompass vascular diseases that are related to hyperlipidemia, such as arteriosclerosis [1-5]. DISGT has been shown to improve the impairment of acetylcholineinduced vasorelaxation responses by inducing endothelial nitric oxide synthase expression, thus reducing the accumulation of atherosclerotic lesions in vivo [2]. As documented in Shang Han Lun, DISGT is five species composed of Rheum undulatum Linne, Prunus Persica (L.) Batsch, Conyza canadensis L., Cinnamomum Cassia Presl, and Glycytthiza uralensis Fischer, that have various pharmacological on the cardiovascular disease or metabolic diaseas $[1,6,7]$. It has been reported to high-fat/ high-cholesterol diet-fed $d b / d b$ mice and western diet fed ApoE mice, DISGT decreased plasma glucose, cholesterol, triglyceride, and LDL cholesterol levels and [8]. Further, DISGT treat chronic hepatitis and amenorrhea. However, the mechanisms involved and effectiveness of DISGT remain unclear in atherosclerosis.

Atherosclerosis is a chronic inflammatory disease that involves increased total cholesterol (T-chole) levels, blood monocyte recruitment, lipid deposition, and macrophage foam cell formation [9, 10]. Recently, the atherosclero-related disease protective potentive of DISGT is suggest based on some studies. DISGT, has been shown to attenuate the increases in T-chole that are induced by a hypercholesterolemic diet in mices, and this action may be due to the promotion of cholesterol $[1,7]$. These results show that DISGT may be useful in the treatment of cardiovascular-metabolic disease. The effects of adenosine monophosphate-activated protein kinase (AMPK) on metabolically relevant organs and tissues, such as the liver, skeletal muscle, adipose tissue, and hypothalamus, are relatively well documented [11]. The notion that AMPK activation could be used to promote vascular health has only recently emerged. In vascular tissues, AMPK activation appears to be a shared molecular target $[12,13]$. Therefore, AMPK activation may improve vascular diseases, including atherosclerosis.

Traditional Korean herbal medicine has been widely used in the treatment of atherosclerosis-related disorders [14]. However, its therapeutic efficacies and mechanisms of action are unclear. Several studies have suggested that DISGT demonstrates therapeutic potential in cardiovascular disease and atherosclerosis. In this study, we investigated the effects of DISGT on atherosclerosis-related markers, including intercellular adhesion molecule-1 (ICAM-1), vascular cell adhesion molecule-1 (VCAM-1), and E-selectin, in high-fat diet (HFD)-induced apolipoprotein E-deficient $\left(\mathrm{ApoE}^{-/-}\right)$mice. In addition, we assessed the effect of DISGT on AMPK signaling, lipid levels, atherosclerotic lesions, and liver histology in these mice.

\section{Methods \\ Preparation of DISGT (Table 1)}

The herbs were purchased from Kwangmyeongdang Medicinal Herbs Co. (Ulsan, Korea) and authenticated based on their microscopic and macroscopic characteristics by the classification and identification committee of the Korea Institute of Oriental Medicine (KIOM).

The formula of DIGST consists of five herbs, including Rheum undulatum Linne (80 g), Prunus Persica (L.) Batsch (60 g), Conyza canadensis L. (40 g), Cinnamomum Cassia Presl (40 g), and Glycyrrhiza uralensis Fischer (40 g), which were mixed and ground into a crude powder. The total mixure (260 g) was boiled in distilled water $(1: 10, \mathrm{v} / \mathrm{v})$ at $100{ }^{\circ} \mathrm{C}$ for $2 \mathrm{~h}$ and the extract was filtered, lyophilized and subsequently stored at $-20{ }^{\circ} \mathrm{C}$. The yield of DISGT aqueous extract was $11.25 \%$ (w/w).

\section{Experimental animals, diet, and treatments}

Male 8 weeks old $A p o E^{-1-}$ mice on a C57BL/6 J background were obtained from SLC Inc., (Shizuoka, Japan). They were housed under diurnal lighting conditions and allowed access to food and tap water ad libitum. All experimental protocols involving the use of animals were conducted in accordance with the National Institutes of Health guidelines and approved (approve number; Kiom 13-037) by the Committee on Animal Care of the Korea Institute of Oriental Medicine (KIOM).

Mice were divided into four groups: (1) Normal diet (ND; $n=8$ ), (2) HFD (41 \% of total calories from fat; $0.21 \%$ cholesterol; Research Diet, New Brunswick, NJ, USA) with saline $(n=8)$, (3) HFD with $300 \mathrm{mg} / \mathrm{kg}$ DISGT $(n=8)$, and (4) HFD with $10 \mathrm{mg} / \mathrm{kg}$ atorvastatin (statin; $n=8$ ). DISGT or statin was dissolved in water and then given orally everyday over a 16-week period, during which the mice were fed a HFD. Control mice received saline.

\section{Analysis of serum markers}

Blood samples were drawn from the aorta under light anesthesia and stored on ice for $30 \mathrm{~min}$ before centrifugation at $13,000 \mathrm{rpm}$ at $4{ }^{\circ} \mathrm{C}$ for $10 \mathrm{~min}$, after which they were stored at $-80{ }^{\circ} \mathrm{C}$. Serum levels of T-chole, high-

Table 1 Composition of Do In Seung Gi-Tang

\begin{tabular}{lll}
\hline Scientific name & Herbal name & Amount (g) \\
\hline Prunus persica (L.) Batsch & Persicae Semen, 桃仁 & 60 \\
Cinnamomum cassia Presl & Cinnamomi Ramulus, 桂枝 & 40 \\
Glycyrrhiza uralensis Fisch & Licorice, 甘草 & 40 \\
Mirabilite & Natrii sulfas, 芒硝 & 40 \\
Rheum palmatum Linne & Rhei Rhizoma, 大黃 & 80 \\
\hline
\end{tabular}


density lipoprotein cholesterol (HDL), low-density lipoprotein cholesterol (LDL), triglyceride (TG), glucose, alanine aminotransferase (ALT), aspartate aminotransferase (AST), and creatinine were measured with an automatic analyzer (Hitachi Co., Tokyo, Japan).

\section{Atherosclerotic lesion analysis}

Mice were anesthetized and euthanized after 16 weeks of HFD or ND. The aortas were washed with phosphate-buffered saline (PBS) and then fixed with $10 \%$ paraformaldehyde overnight. The adventitia was cleaned thoroughly under a dissecting microscope, and fixed aortas were stained with Oil Red $O$ stock solution $(0.3 \%)$ for $1 \mathrm{~h}$. Atherosclerotic lesion areas were quantified using the isolution full-image analysis software (Image and Microscope Technology, Vancouver, Canada).

\section{Histopathology}

Mice were deeply anesthetized with sodium thiopental and subsequently perfused with cold PBS, followed by fixation with $10 \%$ (w/v) paraformaldehyde overnight. Hematoxylin and Eosin (HEE): Livers were embedded in paraffin and sectioned serially at $4 \mu \mathrm{m}$. The sections were stained with $\mathrm{H} \& \mathrm{E}$. The sections were stained with $H \& E$ as described previously [15]. Immunohistochemistry: Livers were removed and fixed in the same solution for $24 \mathrm{~h}$ at $4{ }^{\circ} \mathrm{C}$. Fixed aortas were frozen and stored at $-80{ }^{\circ} \mathrm{C}$. Sections that were $10-\mu \mathrm{m}$ thick were sliced from frozen tissues and then immunostained with antibodies against fatty acid synthase (FAS; Novus Biologicals; Littleton, CO, USA). After additional incubation with the secondary antibody, the chromogen, 3-amino-9-ethylcarbazole, was added to the sections (Vector Laboratories; Burlingame, CA, USA). Reactions with 3,3'-diaminobenzidine substrate (Vector Laboratories) were performed for color development, and the stained sections were then analyzed by light microscopy scanner (3D HISTECH, Budapest, Hungary).

\section{Western blot analysis}

Aortas were homogenized in Tissue protein extraction reagent (Thermo Scientific; Pittsburgh, PA, USA), which was supplemented with a $1 \%$ phosphatase inhibitor cocktail (Sigma-Aldrich Chemical Co.; St. Louis, MO, USA) and protease inhibitors (Roche Applied Science; Basel, Switzerland). The recovered proteins were isolated from aortic tissues, separated by $10 \%$ sodium dodecyl sulfate-polyacrylamide gel electrophoresis, and then transferred onto nitrocellulose membranes (Amersham Biosciences; Piscataway, NJ, USA), according to standard techniques. Blots were probed with primary antibodies directed against VCAM-1 (Santa Cruz Biotechnology;
Santa Cruz, CA, USA), ICAM-1, E-selectin, AMPK, phosphorylated (p)-AMPK, acetyl-COA carboxylase (ACC), p-ACC (Cell Signaling Technology; Beverly, MA, USA), or FAS. This was followed by incubation with the secondary antibody conjugated to horseradish peroxidase (Cell Signaling). Bound secondary antibodies were detected by chemiluminescence, as generated by the peroxidase reaction, and they were measured with an ImageQuant LAS 4000 apparatus (GE Healthcare Life Sciences; Buckinghamshire, UK). The membranes were then reprobed with an anti- $\beta$-actin antibody (Cell Signaling) as the internal sample control.

\section{Quantitative high-performance liquid chropmatography analysis}

The sample was analyzed by reverse phase-high performance liquid chromatography using Waters e2695 liquid chromatography system (Waters Co., Milford, MA, USA), equipped with a Waters 2998 photodiode array detector. Data processing was carried out with the Empower software (Waters Co.). The Phenomenex Luna C18 column $(250 \mathrm{~mm} \times 4.6 \mathrm{~mm}$; particle size $5 \mu \mathrm{m}$; Phenomenex, Torrance, CA, USA) was used as the stationary phase and $1 \%(\mathrm{v} / \mathrm{v})$ acetic acid aqueous solution (A) and acetonitrile $\cdot$ acetic acid (99:1) (B) were used as the mobile phase. The elution conditions involved holding the starting mobile phase at $90 \% \mathrm{~A}$ and $10 \% \mathrm{~B}$ and applying a gradient of $0 \% \mathrm{~A}$ and $100 \% \mathrm{~B}$ for $50 \mathrm{~min}$. A wash with $100 \%$ acetonitrile was applied for $10 \mathrm{~min}$, followed by equilibration at $90 \% \mathrm{~A}$ and $10 \% \mathrm{~B}$ for $10 \mathrm{~min}$. The flow rate was $1.0 \mathrm{~mL} / \mathrm{min}$ and the injection volume for all the samples was $20 \mu \mathrm{L}$. Peaks were identified by comparing retention times and UV spectra with those of commercial standards. Components were quantified based on peak areas at $220 \mathrm{~nm}$. Quantitation was performed based on a mixture of external standards of known concentration, which were analyzed in duplicate before and after analyzing the samples. Peak areas were used to calculate the quantities of compounds in the samples. The calibration curves of the standards ranging from 11.9 to $243 \mu \mathrm{g} / \mathrm{mL}$ (five levels) revealed good linearity, with $\mathrm{R}^{2}$ values exceeding 0.999 (peak area vs. concentration). HPLC-grade reagents, acetonitrile and water were obtained from J. T. Baker (Phillipsburg, NJ, USA).

\section{Data analysis}

Values are expressed as the mean \pm standard error of the mean (SEM). Statistical comparisons were performed using unpaired Student's t-tests and analysis of variance (ANOVA) for repeated measures followed by post hoc pairwise comparisons in SigmaPlot software version 13.0 (Systat Software Inc.; San Jose, CA, USA). Differences were considered significant at $p<0.05$. 


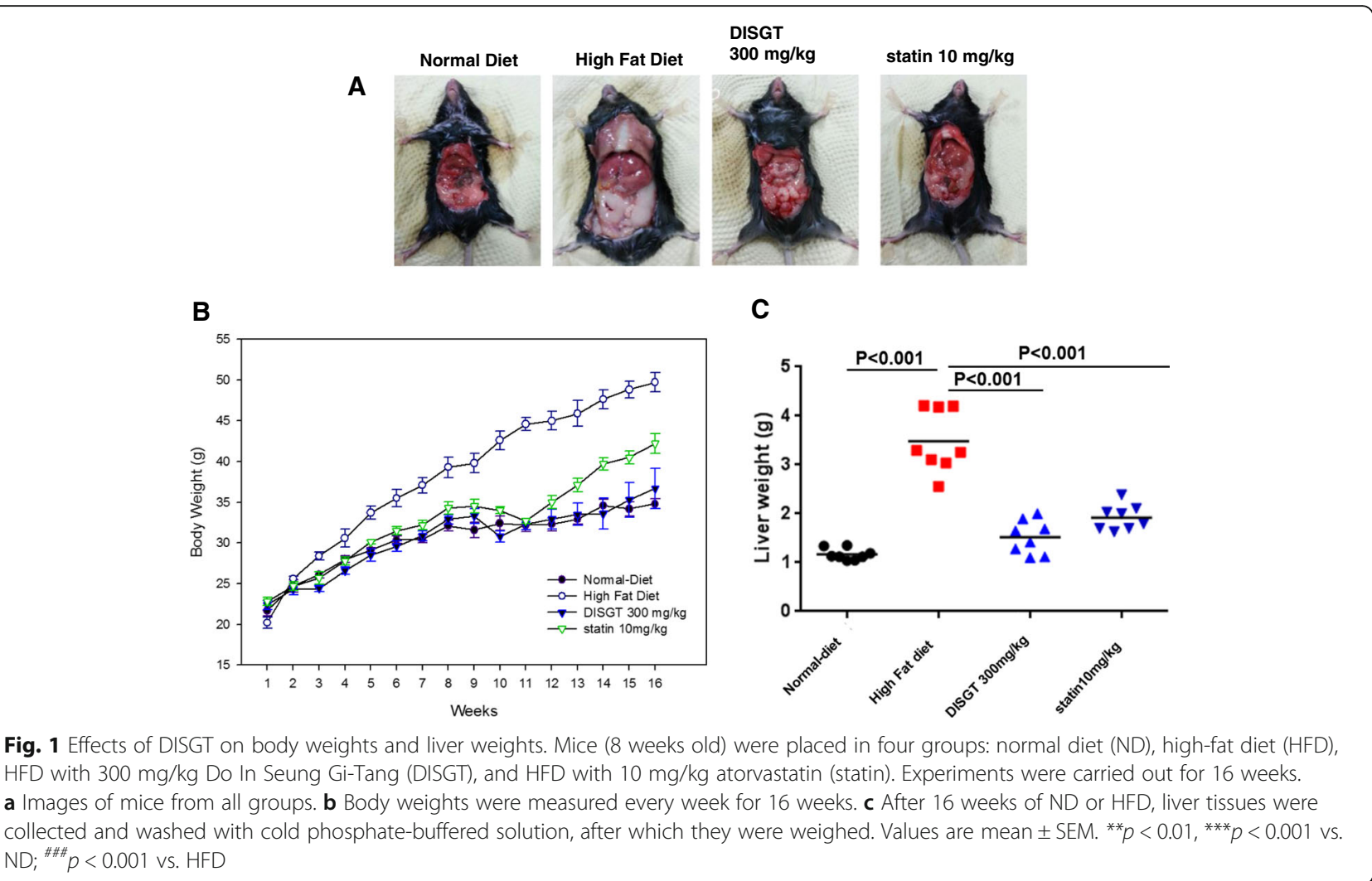

\section{Results}

Effect of DISGT on body weight, liver weight, and serum parameters in HFD-induced $\mathrm{ApoE}^{-/-}$mice

The body weight, liver weight, and serum parameters were measured in mice. HFD-fed ApoE ${ }^{-/-}$mice showed significantly increased body weight compared with ND-fed mice $(34.8 \pm 0.59$ vs. $49.7 \pm 1.16 \mathrm{~g}, p<0.001)$. However, treatment of HFD-fed mice with DISGT or statin decreased the body weight (Fig. 1a-b and Table $2 ; 36.7 \pm 2.48$ or 42.2 \pm 1.24 g vs. HFD group; $p<0.001$ ). Furthermore, the liver weights showed an increased in the HFD-fed ApoE $^{-/-}$ mice $(p<0.001)$, and the elevated liver weight was reduced by DISGT (Fig. 1c and Table 2; $p<0.001$, versus HFD group). In addition, HFD-fed mice showed significantly higher serum levels of T-chole, LDL, TGs, glucose, AST, ALT, and creatinine than that of ND-fed mice. These levels were all significantly reduced by DISGT or statin treatment (Table 3).

\section{Effect of DISGT on atherosclerotic lesions in aortas}

The extent of atherosclerotic lesions in the aorta was determined by isolution analysis, and it was confined to the cross-section of the aortic root. Oli Red O staining was used to detect atherosclerotic plaques. The aortic root lesion area was markedly increased in HFD-fed mice (27.72 $\pm 2.87 \mathrm{~mm}^{2} ; p<0.01$ ), and it was significantly reduced by treatment with DISGT or statin $\left(7.24 \pm 1.81 \mathrm{~mm}^{2}\right.$ or 11.90 $\pm 1.07 \mathrm{~mm}^{2} ; p<0.01$ ) (Fig. $2 \mathrm{a}$ and $\mathrm{b}$ ). As demonstrated by

Table 2 Body weight and liver weight

\begin{tabular}{|c|c|c|c|c|}
\hline & & & DISGT & Statin \\
\hline & ND & HFD & $300 \mathrm{mg} / \mathrm{kg}$ & $10 \mathrm{mg} / \mathrm{kg}$ \\
\hline \multicolumn{5}{|l|}{ Body weight (g) } \\
\hline Initial body weight & $21.70 \pm 0.64$ & $20.20 \pm 0.67$ & $22.40 \pm 0.57$ & $22.80 \pm 0.50$ \\
\hline Final body weight & $34.80 \pm 0.59$ & $49.70 \pm 1.16^{* * *}$ & $36.70 \pm 2.48^{\# \# \#}$ & $42.20 \pm 1.24^{\# \# \#}$ \\
\hline Body weight gain & $13.10 \pm 0.63$ & $29.50 \pm 0.98^{* * *}$ & $14.30 \pm 1.00^{\# \# \#}$ & $19.40 \pm 0.65^{\# \# \#}$ \\
\hline Liver weight (g) & $1.17 \pm 0.05$ & $3.48 \pm 0.24^{* * *}$ & $1.52 \pm 0.13^{\# \# \#}$ & $1.92 \pm 0.10^{\# \# \#}$ \\
\hline
\end{tabular}

Abbreviations: HFD high-fat diet, DISGT Do In Seung Gi-Tang

All data represent mean values $\pm \operatorname{SEM}(n=8)$

${ }^{* * *} p<0.001$, vs. $A p o E^{-/-}$mice without HFD (ND; Normal diet)

$\# \#<0.001$, vs. HFD-fed $A p o E^{-1-}$ mice (HFD) 
Table 3 Lipid parameters

\begin{tabular}{|c|c|c|c|c|}
\hline & & & DISGT & Statin \\
\hline & ND & HFD & $300 \mathrm{mg} / \mathrm{kg}$ & $10 \mathrm{mg} / \mathrm{kg}$ \\
\hline$\overline{\text { T-chole (mg/dL) }}$ & $401.86 \pm 21.18$ & $1401.71 \pm 69.66^{* * *}$ & $951.43 \pm 56.72^{\# \# \#}$ & $1145.00 \pm 75.60^{\#}$ \\
\hline $\mathrm{LDL}(\mathrm{mg} / \mathrm{dL})$ & $71.86 \pm 2.08$ & $368.29 \pm 17.88^{* * *}$ & $244.14 \pm 13.48^{\# \# \#}$ & $316.33 \pm 18.48^{\#}$ \\
\hline $\mathrm{HDL}(\mathrm{mg} / \mathrm{dL})$ & $22.14 \pm 1.27$ & $11.71 \pm 1.14^{* * *}$ & $12.57 \pm 1.15$ & $13.17 \pm 2.71$ \\
\hline $\mathrm{TG}(\mathrm{mg} / \mathrm{dL})$ & $34.57 \pm 2.51$ & $278.71 \pm 16.06^{* * *}$ & $43.29 \pm 13.11^{\# \# \#}$ & $75.83 \pm 2.42^{\# \# \#}$ \\
\hline Glucose (mg/dL) & $134.29 \pm 4.40$ & $422.71 \pm 36.80^{* * *}$ & $201.29 \pm 12.79^{\# \# \#}$ & $298.50 \pm 12.83^{\# \#}$ \\
\hline AST $(U / L)$ & $50.29 \pm 7.06$ & $571.57 \pm 22.64^{* * *}$ & $333.29 \pm 25.70^{\# \# \#}$ & $370.83 \pm 12.62^{\# \# \#}$ \\
\hline $\mathrm{ALT}(\mathrm{U} / \mathrm{L})$ & $29.86 \pm 1.71$ & $562.43 \pm 14.32^{* * *}$ & $247.86 \pm 33.41^{\# \# \#}$ & $277.00 \pm 20.91^{\# \# \#}$ \\
\hline Creatinine (mg/dL) & $0.21 \pm 0.02$ & $0.35 \pm 0.03^{* *}$ & $0.17 \pm 0.02^{\# \# \#}$ & $0.25 \pm 0.03$ \\
\hline
\end{tabular}

Abbreviations: HFD high-fat diet, DISGT Do In Seung Gi-Tang, T-chole total cholesterol, LDL low-density lipoprotein, HDL high-density lipoprotein, TG triglyceride, AST aspartate aminotransferase, $A L T$ alanine aminotransferase

All data represent mean values $\pm \operatorname{SEM}(n=8)$

${ }^{* *} p<0.01,{ }^{* * *} p<0.001$, versus $A^{*}{ }^{*} E^{-1}$ mice without HFD (ND)

${ }^{\#} p<0.05,{ }^{\# \#} p<0.01$, and ${ }^{\# \# \#} p<0.001$, versus HFD-fed $A p o E^{-1}$ mice (HFD)

western blot analysis, the expression of ICAM-1, VCAM1 , and E-selectin in HFD-fed mice was significantly increased compared with that in ND-fed mice. In contrast, DISGT- or statin-treated mice showed lower expression levels of ICAM-1, VCAM-1, and E-selectin compared with HFD-fed mice (Fig. 2c), and this decrease by DISGT was statistically significant (Fig. 2d).

\section{Histology of liver}

The accumulation of lipids in the liver impairs hepatocyte function, which leads to hyperglycemia via hepatic glucose production. The staining of liver tissues with $\mathrm{H} \& \mathrm{E}$ and Oil Red O was analyzed. Lipid droplets accumulated in the livers of HFD-fed mice, and this accumulation was decreased with DISGT or statin treatment

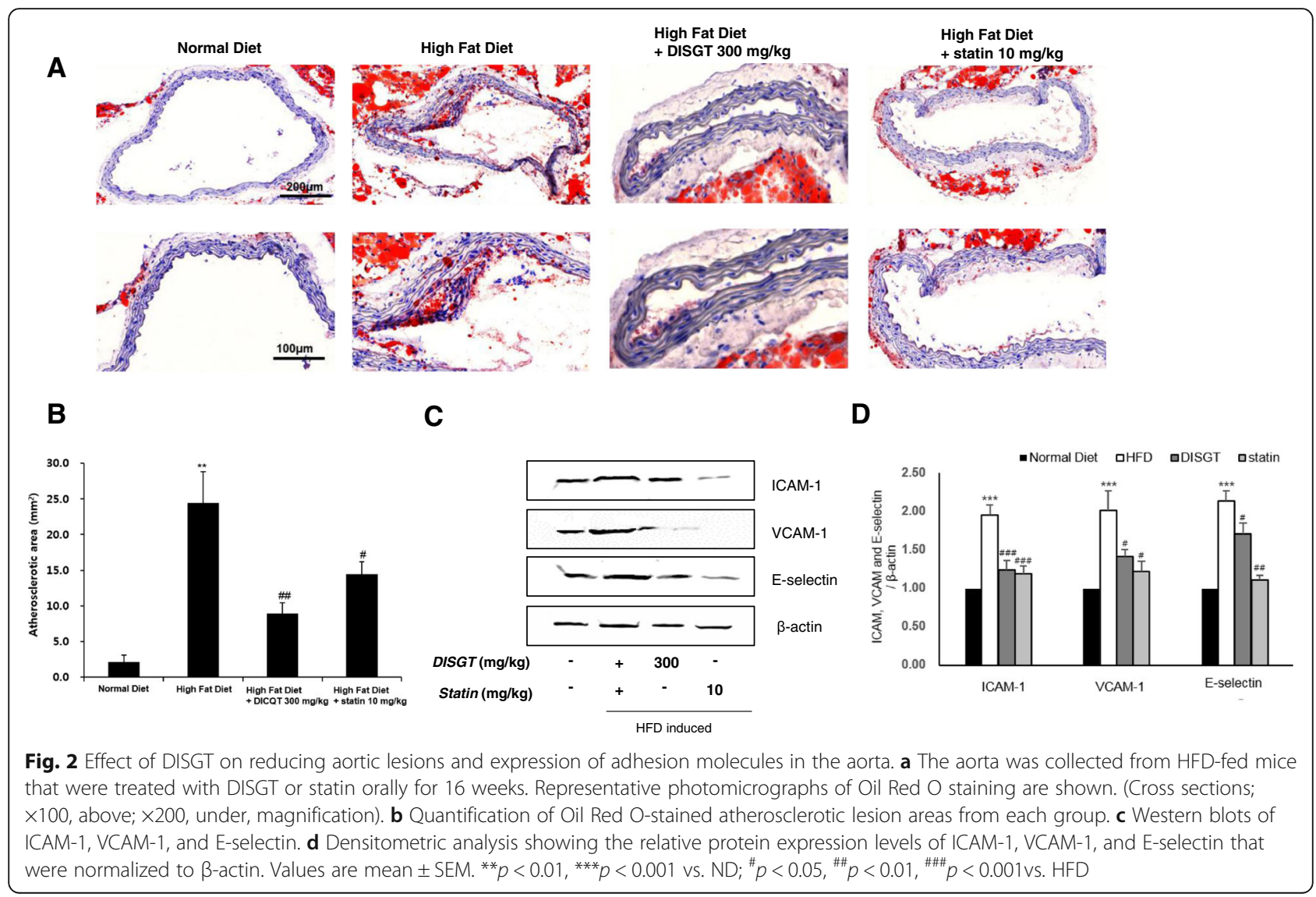



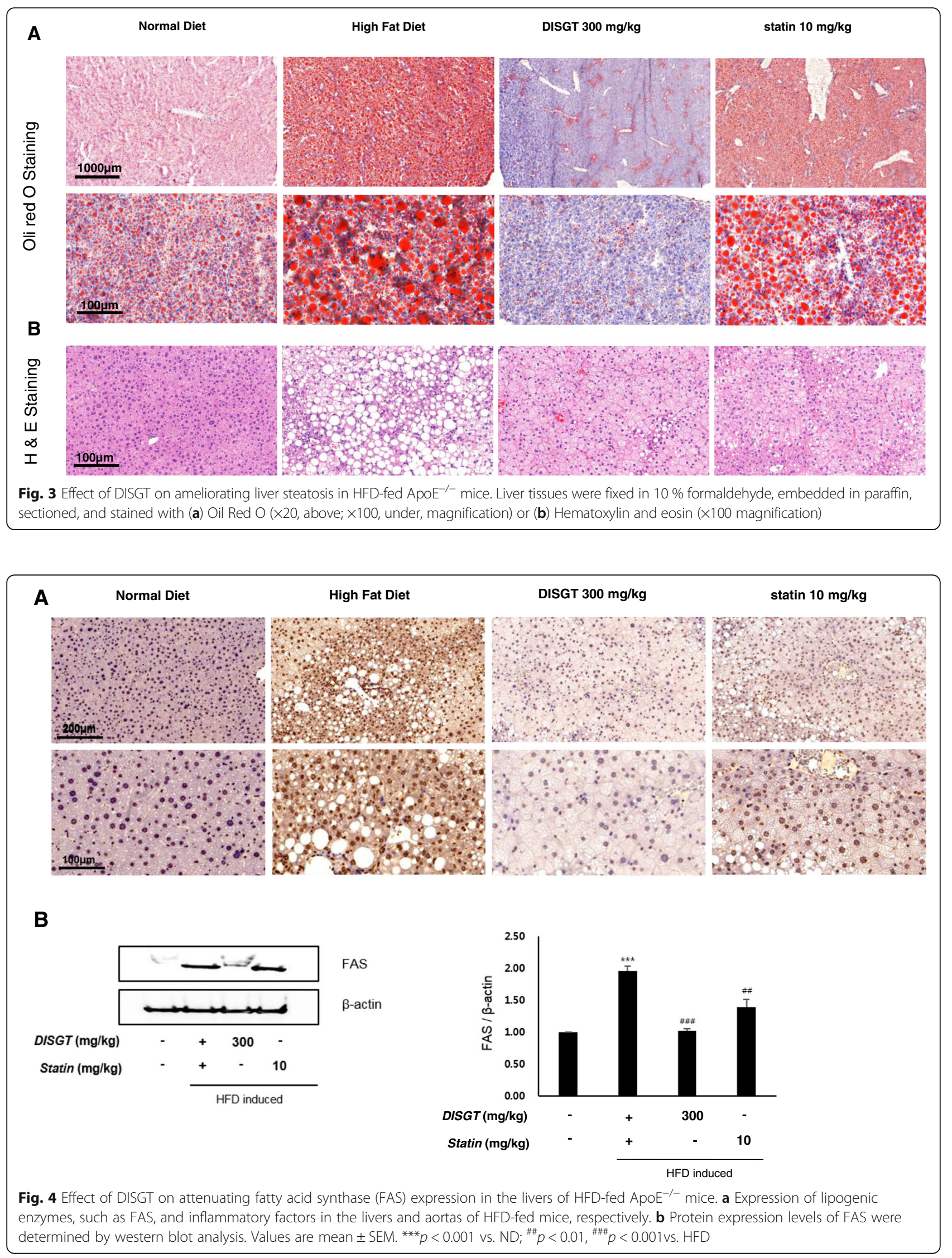
(Fig. 3a). Furthermore, DISGT reduced sizes of adipocytesation and inflammation, as demonstrated by decreased H\&E staining (Fig. 3b).

\section{Effect of DISGT on FAS expression}

FAS is involved in the synthesis of fatty acids and TGs, and it is known to be upregulated in HFD-fed mice. The expression of FAS in liver tissues of HFD-fed mice was reduced by DISGT or statin treatment (Fig. 4a). Also, the effect of DISGT on decreasing FAS expression was further confirmed by western blotting (Fig. 4b).

\section{Effect of DISGT on the expression of the AMPK pathway in liver tissues}

AMPK plays a crucial role in fatty acid metabolism, and it has demonstrated potential therapeutic impact in atherosclerosis. The protein levels of AMPK and ACC were assessed in liver tissues of $\mathrm{ApoE}^{-/-}$mice. Interestingly, DISGT increased the phosphorylation of AMPK in liver tissues. ACC phosphorylation, which is an index of
AMPK activation, was also consistently detected in these tissues (Fig. 5a and b).

\section{Quantitative high-performance liquid chropmatography analysis of DISGT}

The HPLC analysis of the DISGT revealed three peaks matching those of the commercial standards cinnamic acid, glycyrrhizic acid, and amygdalin with retention times of approximately $20.5 \mathrm{~min}, 23.0 \mathrm{~min}$, and $33.5 \mathrm{~min}$, respectively (Fig. 6). The DISGT contained $0.104 \pm 0.006 \mathrm{mg} / \mathrm{g}$ cinnamic acid, $1.901 \pm 0.013 \mathrm{mg} / \mathrm{g}$ glycyrrhizic acid, and $2.566 \pm$ $0.007 \mathrm{mg} / \mathrm{g}$ amygdalin (Table 4).

\section{Discussion}

The Korean herbal medicine DISGT, has been shown to prevent vascular or liver inflammatory responses and lipid deposition in vivo. Currently, it is used to treat blood stasis by promoting blood circulation. In this study, we evaluated the anti-atherosclerotic properties of DISGT.

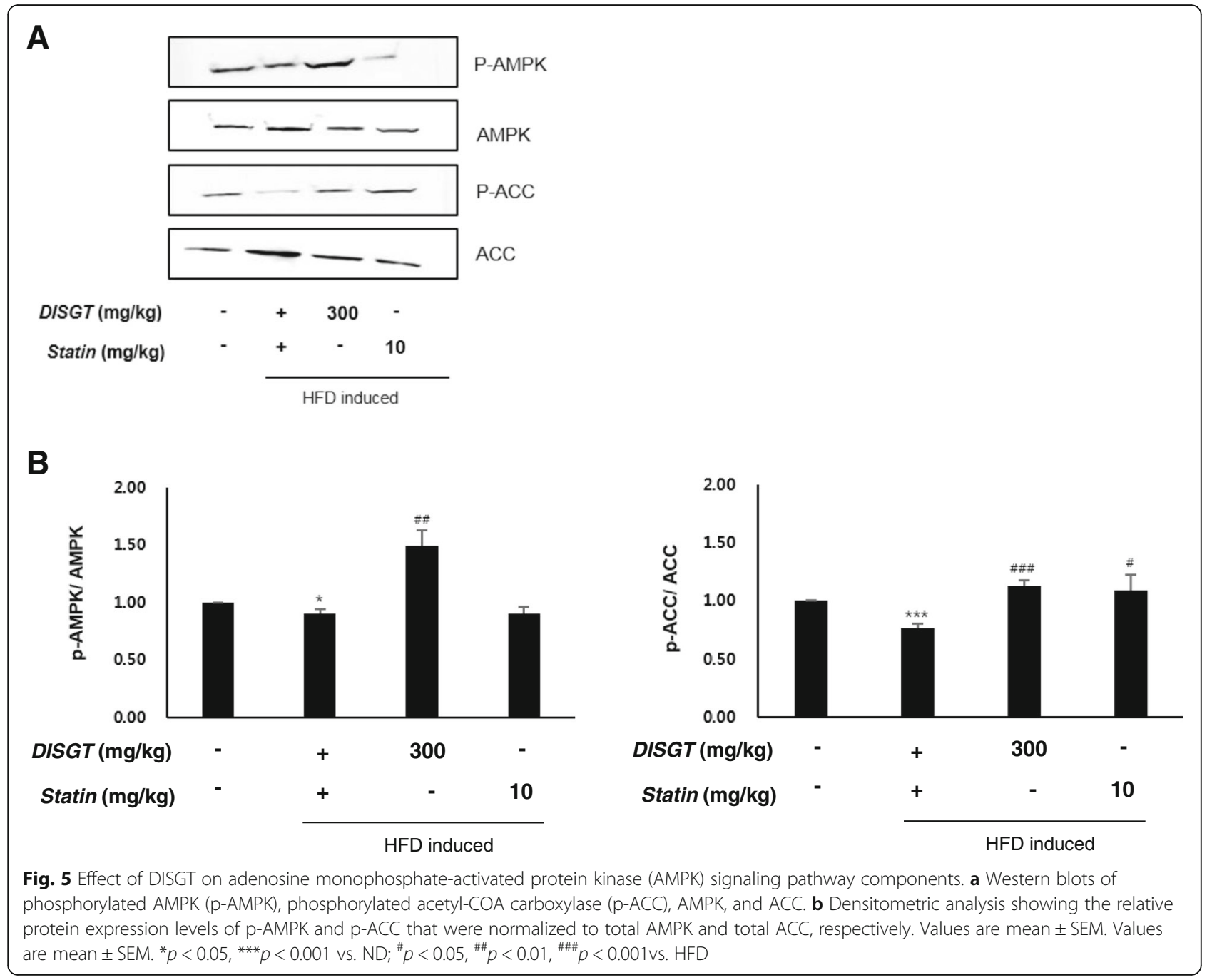




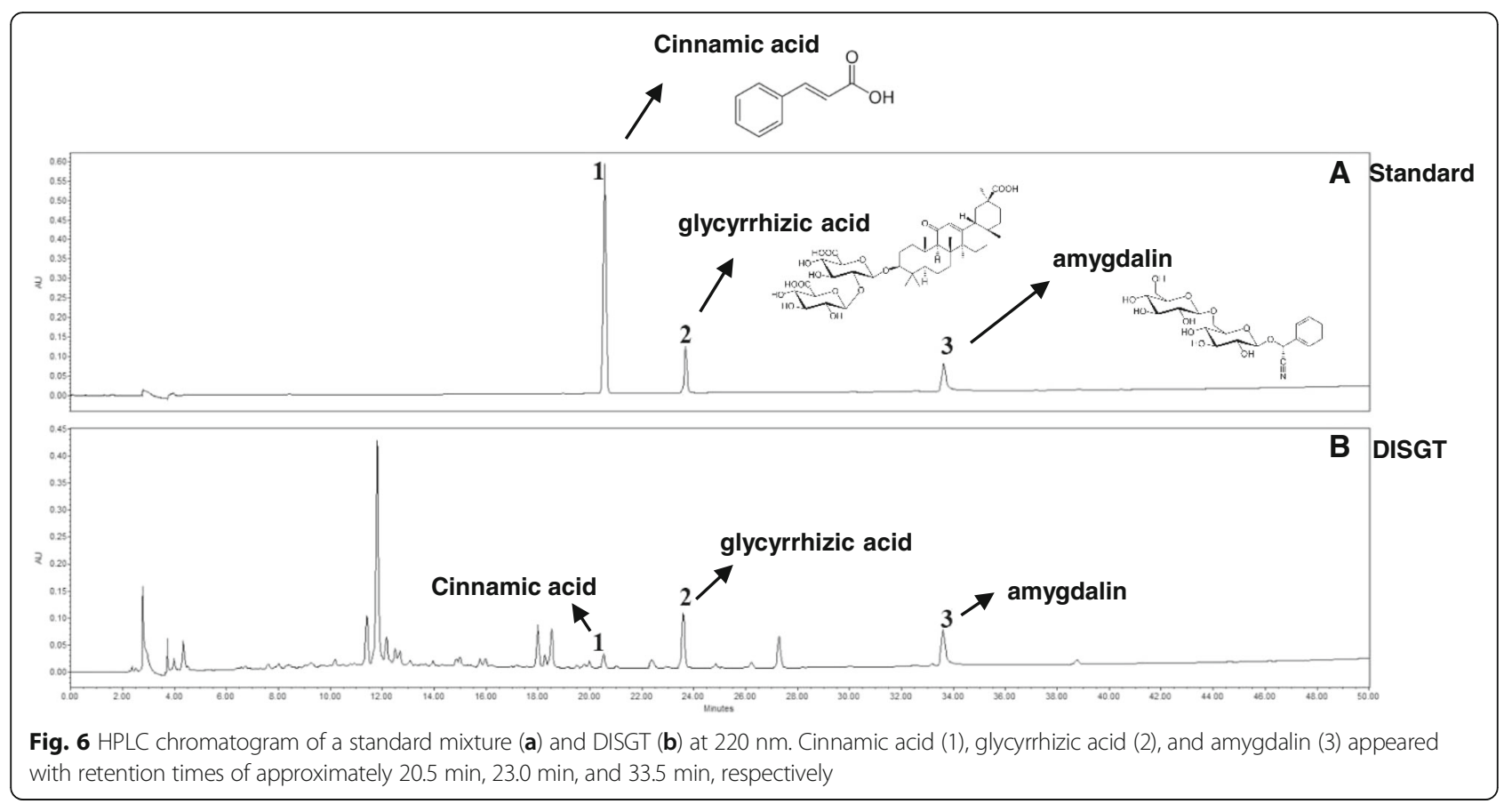

Our findings show that DISGT reduced body weight, liver weight, and the serum levels of T-chole, LDL, TGs, and glucose, in HFD-fed $\mathrm{ApoE}^{-/-}$mice. No changes in HDL were observed. DISGT also significantly attenuated the severity of atherosclerotic lesions and reduced the expression of adhesion molecules in the aortas of HFDfed mice. In addition, the increased accumulation of inflammatory cells and hepatic steatosis in the liver tissues were observed in the HFD group compared with the ND group. However, DISGT inhibited these changes in HFD-fed mice. Importantly, the AMPK pathway is a regulator of metabolic homeostasis. DISGT markedly reduced the expression of FAS and p-ACC and increased the expression of $\mathrm{p}$-AMPK. These data suggest that DISGT activates AMPK to exert anti-atherosclerotic effects.

Because AMPK is a cellular energy sensor, understanding the mechanism by which hepatic AMPK coordinates hepatic energy metabolism is important. The dysfunction of the AMPK signaling pathway is involved in the development of various cardiovascular diseases, including atherosclerosis $[9,16]$. AMPK inhibits the expression of adhesion molecules and E-selectin in endothelial cells

Table 4 Average contents of the reference compounds in DISGT

\begin{tabular}{lc}
\hline Compound & Average content $(\mathrm{mg} / \mathrm{g})$ \\
\hline Cinnamic acid & $0.104 \pm 0.006$ \\
Glycyrrhizic acid & $1.901 \pm 0.013$ \\
Amygdalin & $2.566 \pm 0.007$ \\
\hline
\end{tabular}

that have been exposed to hydrogen peroxide, tumor necrosis factor-alpha, or fatty acids [12, 17, 18]. In the liver, AMPK activation stimulates fatty acid oxidation and inhibits lipogenesis, and lipid metabolism is reduced by adiponectin $[17,18,19]$. Recent studies have suggested that AMPK is a therapeutic target of atherosclerosis, because it reduces vascular inflammation and fatty acid synthesis to attenuate atherosclerosis $[13,18,20]$.

Many studies have focused on the effects of dietary fatty acids or vascular inflammation on lipid and lipoprotein metabolism with regard to the risk of atherosclerosis. However, fatty acids can also influence a number of other relevant mechanisms that are involved in atherosclerosis, such as lipid peroxidation, vascular inflammation, and hemostasis [21-23]. In our study, DISGT attenuated the accumulation of lipids in the liver and the presence of atherosclerotic lesions in the aorta. Furthermore, the expression levels of AMPK-regulated lipoxidation factors, inflammatory compounds, and adhesion molecules were significantly decreased in the livers and aortas of DISGTtreated, HFD-fed mice. This indicates that DISGT activates AMPK, thereby preventing the vascular inflammatory response and lipid deposition.

Interestingly, statins did not lower total cholesterol but had a major effect on TG levels in the current study. These results are different than those expected in humans. Clinically established statins have long been known to exert anti-atherosclerotic effects. However, recent studies have suggested that the effects of statins on cholesterol in mice are different than those in humans. For instance, statin treatment does not decrease 
cholesterol levels in $\mathrm{ApoE}^{-1-}$ mice. This can be explained by the lack of ApoE, which is a ligand for the LDL receptor and is necessary for LDL clearance. Thus, the cholesterol-independent effects of statins can be more effectively studied in mice than in humans [23-25].

Cholesterol crystals have been reported to be the metabolic signals that trigger sterile inflammation in atherosclerosis [26]. Previous studies have shown that AMPK is a key player in maintaining physiological processes in the heart and vasculature [12, 27], and it regulates lipoxidation genes [28]. Results from these studies support our data and suggest that AMPK modulates the effect of DISGT on lowering inflammation and lipid deposition to reduce atherosclerosis. Most importantly, DISGT protected the vasculature against the initiation and development of atherosclerosis.

\section{Conclusions}

DISGT prevented the development of atherosclerotic lesions, the expression of vascular inflammatory markers, and the accumulation of lipids in HFD-fed $\mathrm{ApoE}^{-/-}$mice. This was associated with increases in AMPK levels. Therefore, DISGT may exert its anti-atherosclerotic effects by activating AMPK. Moreover, DISGT has the potential for use as a therapeutic drug for the treatment of atherosclerosis. Further studies are needed to identify and classify the active components of the herbal mixture and clinical trial.

\section{Acknowledgements}

This research was supported by Project (K16090) "Research for developing of classification criteria and management technique of Mibyeong" of the Korea Institute of Oriental Medicine.

\section{Funding}

Not available.

\section{Availability of data and material}

All the data are presented within the manuscript.

\section{Authors' contributions}

SHP, HKK participated in the design of the study. SHP carried out the experiments, analyzed the data, and wrote the manuscript. YYS and KJN carried out the animal study support and SJ analysed high-performance liquid chromatography (HPLC), KYC performed selected drug and advice by drug. All authors read and approved the final manuscript.

\section{Competing interests}

The authors declare that they have no competing interests.

\section{Consent for publication}

Not applicable.

\section{Ethics approval and consent to participate}

Ethic approval was obtained from the Committee on Animal Care of the Korea Institute of Oriental Medicine (KIOM); approve number: Kiom 13-037.

\section{Author details}

'Mibyeong Research Center, Korea Institute of Oriental Medicine, 1672 Yuseong-daero, Yuseong-gu, Daejeon 305-811, South Korea. ${ }^{2}$ Department of Korean Medical Science, School of Korean Medicine, Pusan National University, Gyeongnam, Yangsan 626-870, South Korea. ${ }^{3} \mathrm{~K}$-herb Research
Center, Korea Institute of Oriental Medicine, 1672 Yuseong-daero, Yuseong-gu, Daejeon 305-811, South Korea.

Received: 18 March 2016 Accepted: 20 August 2016

Published online: 08 September 2016

\section{References}

1. Yoon, JJ, Lee YJ, Park OJ, Lee SM, Lee YP, Cho NG, Kang DG, Lee HS Doinseunggitang ameliorates endothelial dysfunction in diabetic atherosclerosis. Evidence-Based Complementary and Alternative Medicine. 2013:2013:783576. doi:10.1155/2013/783576.

2. Heo Jun. DongUiBoGam (東醫寶鑑). Kiom Library, South of Korea, p1117.

3. Chen Q. Pharmacology and application of chiness herbs. Taipei: SMC; 1989.

4. Song MY, Chung SH, Lee JS, Kim SS, Shin HD. The study on pharmacological treatment of obesity in western and oriental medicine. Korean J Orient Med. 1999;4:55-65.

5. Lai TY, Weng YJ, Kuo WW, Chen LM, Chung YT, Lin YM, Tsai FJ, Lee CH, Choong YM, Lai EY, Huang CY, Yeh YL. Taohe Chengqi Tang ameliorates acute liver injury induced by carbon tetrachloride in rats. J Chin Integr Med. 2010:8:49-55.

6. Lee YJ, Kim EK, Kim HY, Yoon JJ, Lee SM, Lee YP, Lee GM, Kang DG, Lee HS. Therapeutic effect of Doinseungi-tang on diabetic vascular dysfunction. Herb Formula Sci. 2013;21:119-30.

7. Sung YY, Kim DS, Choi GY, Kim SH, Kim HK. Dohaekseunggi-tang extract inhibits obesity, hyperlipidemia, and hypertension in high-fat diet-induced obese mice. BMC Complement Altern Med. 2014;14:372.

8. Lee YJ, Kin EK, Kim HY, Yoon JJ, Lee SM, Lee GM, Kang DG, Lee HS. Therapeutic effect of Doinseunggi-tang on diabetic vascular dysfunction. Herb Formul Sci. 2013;21(1):119-30. 10.14374/HFS.2013.21.1.119.

9. Ho FM, Liao YH, Yang AJ, Lee Chao PD, Hou YC, Huang CT, Lin SR, Lee KR, Huang KC, Lin WW. Anti-atherosclerotic action of Ger-Gen-Chyn-Lian-Tang and AMPK-dependent lipid lowering effect in hepatocytes. J Ethnopharmacol. 2012;142:175-87.

10. Zeng Y, Li C, Guan M, Zheng Z, Li J, Xu W, Wang L, He F, Xue Y. The DPP-4 inhibitor sitagliptin attenuates the progress of atherosclerosis in apolipoprotein-E-knockout mice via AMPK- and MAPK-dependent mechanisms. Cardiovasc Diabetol. 2014;13:32.

11. Cantó C, Auwerx J. AMP-activated protein kinase and its downstream transcriptional pathways. Cell Mol Life Sci. 2010;67:3407-23.

12. Shirwany NA, Zou MH. AMPK in cardiovascular health and disease. Acta Pharmacol Sin. 2010;31:1075-84.

13. Wang Q, Zhang M, Liang B, Shirwany N, Zhu Y, Zou MH. Activation of AMPactivated protein kinase is required for berberine-induced reduction of atherosclerosis in mice: the role of uncoupling protein 2. PLoS One. 2011;6:e25436.

14. Kim BJ, Kim YK, Park WH, Ko JH, Lee YC, Kim CH. A water-extract of the Korean traditional formulation Geiji-Bokryung-Hwan reduces atherosclerosis and hypercholesteremia in cholesterol-fed rabbits. Int Immunopharmacol. 2003:3:723-34.

15. Li Y, Xu S, Mihaylova MM, Zheng B, Hou X, Jiang B, Park O, Luo Z, Lefai E, Shyy JY, Gao B, Wierzbicki M, Verbeuren TJ, Shaw RJ, Cohen RA, Zang M. AMPK phosphorylates and inhibits SREBP activity to attenuate hepatic steatosis and atherosclerosis in diet-induced insulin-resistant mice. Cell Metab. 2011;13:376-88.

16. Viollet B, Guigas B, Leclerc J, Hébrard S, Lantier L, Mounier R, Andreelli F, Foretz M. AMP-activated protein kinase in the regulation of hepatic energy metabolism: from physiology to therapeutic perspectives. Acta Physiol (Oxf). 2009:196:81-98.

17. Dixit M, Bess E, Fisslthaler B, Härtel FV, Noll T, Busse R, Fleming I. Shear stress-induced activation of the AMP-activated protein kinase regulates FoxO1a and angiopoietin-2 in endothelial cells. Cardiovasc Res. 2008;77: 160-8.

18. Cacicedo JM, Yagihashi N, Keaney Jr JF, Ruderman NB, Ido Y. AMPK inhibits fatty acid-induced increases in NF-kappaB transactivation in cultured human umbilical vein endothelial cells. Biochem Biophys Res Commun. 2004:324: 1204-9.

19. Chen H, Zhang L, Li X, Li X, Sun G, Yuan X, Lei L, Liu J, Yin L, Deng Q, Wang J, Liu Z, Yang W, Wang Z, Zhang H, Liu G. Adiponectin activates the AMPK signaling pathway to regulate lipid metabolism in bovine hepatocytes. J Steroid Biochem Mol Biol. 2013;138:445-54. 
20. Xu Q, Si LY. Protective effects of AMP-activated protein kinase in the cardiovascular system. J Cell Mol Med. 2010;14:2604-13.

21. Thijssen MA, Mensink RP. Fatty acids and atherosclerotic risk. Handb Exp Pharmacol. 2005:170:165-94.

22. Packard RR, Libby P. Inflammation in atherosclerosis: from vascular biology to biomarker discovery and risk prediction. Clin Chem. 2008:54:24-38.

23. Zadelaar S, Kleemann R, Verschuren L, de Vries-Van der Weij J, van der Hoorn J, Princen HM, Kooistra T. Mouse models for atherosclerosis and pharmaceutical modifiers. Arterioscler Thromb Vasc Biol. 2007:27:1706-21.

24. Roth L, Rombouts M, Schrijvers DM, Martinet W, De Meyer GR. Cholesterolindependent effects of atorvastatin prevent cardiovascular morbidity and mortality in a mouse model of atherosclerotic plaque rupture. Vascul Pharmacol. 2016;80:50-8

25. Tenger C, Zhou X. Apolipoprotein E modulates immune activation by acting on the antigen-presenting cell. Immunology. 2003;109:392-7.

26. Freigang S, Ampenberger F, Weiss A, Kanneganti TD, Iwakura Y, Hersberger M, Kopf M. Fatty acid-induced mitochondrial uncoupling elicits inflammasome-independent IL-1a and sterile vascular inflammation in atherosclerosis. Nat Immunol. 2013;14:1045-53.

27. Steinberg GR, Kemp BE. AMPK in health and disease. Physiol Rev. 2009;89: 1025-78.

28. Motoshima H, Goldstein BJ, Igata M, Araki E. AMPK and cell proliferationAMPK as a therapeutic target for atherosclerosis and cancer. J Physiol. 2006; $1: 63-71$

\section{Submit your next manuscript to BioMed Central} and we will help you at every step:

- We accept pre-submission inquiries

- Our selector tool helps you to find the most relevant journal

- We provide round the clock customer support

- Convenient online submission

- Thorough peer review

- Inclusion in PubMed and all major indexing services

- Maximum visibility for your research

Submit your manuscript at www.biomedcentral.com/submit 